\title{
The Yin-Yang of microvesicles (exosomes) in cancer biology
}

\author{
Khalid Al-Nedawi ${ }^{1,2}$ * \\ 1 Department of Medicine, McMaster University, Hamilton, ON, Canada \\ 2 St. Joseph's Healthcare, Hamilton, ON, Canada \\ *Correspondence: alnedaw@mcmaster.ca \\ Edited by: \\ Aurelie De Thonel, INSERM U866, France \\ Reviewed by: \\ Frederique Gaits-lacovoni, INSERM U1048, France \\ Adriana De Siervi, Instituto de Biologia y Medicina Experimental, Argentina
}

Keywords: microvessels, exosomes, PTEN, metastasis, progression
Microvesicles and exosomes have emerged as a new mode of intercellular communication in cancer. In recent years, microvesicles have received increasing attention from the scientific community for their role in regulating and transferring active molecules responsible for tumor progression and metastasis. Controversy arises from the fact that microvesicles can transfer tumor-promoting molecules such as oncoproteins (1-3), and tumor suppressors (4, $5)$. So, how can we make sense of this controversy?

By considering what we know of cancer development, we can rectify the seemingly opposing findings of the role of microvesicles in this process. The role of oncogenes in the progression of cancer is a wellinvestigated matter, and it is known that cancer progression is dependent on overexpression or mutation of oncogenic proteins. On the other hand, it also depends on loss or downregulation of tumor suppressor proteins.

The effect of the intercellular exchange of oncoproteins and tumor suppressor proteins through microvesicles on cancer progression most probably follows the "Yin-Yang" concept. The availability of microvesicles rich in oncoproteins or those containing tumor suppressors will decide the new phenotype characteristics acquired by the acceptor cells. In the case of the tumor suppressor PTEN, it is interesting to note that metastases often have no expression of PTEN, although the primary tumor itself expresses PTEN (6). This may indicate that cells capable of initiating metastasis originate from cellular selection (7), whereby cells with little or no expression of PTEN are more likely to initiate successful metastases $(8,9)$. Furthermore, it is known from a series of studies of two tumor systems that tumors "talk" to each other through serum-borne factors (1012). A tumor at one side of an experimental animal can affect the dynamics of a tumor on the other side. However, the serumborne factors suggested in these studies are not fully defined; microvesicles represent a reasonable candidate as a player in this form of cellular communication. Such a mode of cellular communication may have a role in tumor metastasis.

Microvesicles that contain PTEN are shed from primary PTEN-expressing tumors to the bloodstream, and may represent the serum-borne factors that are used by the primary tumor to affect the growth of metastases not expressing PTEN. This may indicate a successfully adopted mechanism throughout the natural history of cancer development, in which PTEN-null cells in the primary tumor form "tumor's progeny" in the form of metastases. These metastases may be more aggressive than the primary tumor, because they do not express PTEN. The primary tumor then controls the growth of its "progeny" through tumor suppressor (PTEN) enriched microvesicles, which circulate in the blood and keep PTEN-null metastases in dormancy by supplementing them with PTEN protein. This hypothesis may explain the known phenomenon in which removal of the primary tumor enhances the growth of metastases, because the source of the PTEN-bearing microvesicles is removed.
On the other hand, microvesicles enriched with oncogenic proteins may be shed by tumor cells to oppose the increased metabolic demand associated with overexpression of oncogenic proteins. Oncogenic protein expressing microvesicles are also used as intercellular mediators to engage other cells (which may be healthy) to provide a suitable growth niche to nourish cancer cells. For example, EGFRbearing microvesicles stimulate endothelial cells to secrete vascular endothelial growth factor (VEGF) and the autophosphorylation of the VEGF receptor-2 (VEGFR2), triggering the angiogenic switch to initiate angiogenesis (1).

It is noteworthy that microvesicles also contribute to the transfer of other molecules such as mRNAs and miRNA (miR), which can have various effects on tumor progression by modulating tumor microenvironment. An interesting crosstalk was found between hepatocarcinoma cells, whereby cells expressing miR- 122 send this miR via microvesicles to inhibit the proliferation of miR-122 deficient cells. In a reciprocal process, miR-122 deficient cells secrete insulin-like growth factor to decrease miR-122 expression in miR122 expressing cells (13). Microvesicles from cancer cells are found to stimulate tumor-associated macrophages to secrete VEGF, through the transfer of miR-150 (14) and thereby enhance tumorigenicity. In an opposite effect, macrophages inhibit proliferation of hepatocarcinoma cells by transferring miR-142 and miR223 via microvesicles (15). A similar effect is found for microvesicles from marrow stromal cells expressing miR-146, 
which inhibit the proliferation of glioma cells (16).

In this sense, the role of microvesicles that contain molecules whose effects are seemingly in opposition (oncoproteins, oncomirs, or tumor suppressors) may be reconciled from the perspective of the tumor, a successful parasitic organ generated from our own cells. We realize that this commentary may contain some speculations, but we hope that it can trigger serious discussions in tumor biology, which may contribute to the long battle against the killer known as cancer.

\section{ACKNOWLEDGMENTS}

This work is supported by Prostate Cancer Canada, Movember Foundation (grant no. D2013-2: to Dr. K. Al-Nedawi).

\section{REFERENCES}

1. Al-Nedawi K, Meehan B, Kerbel RS, Allison AC, Rak J. Endothelial expression of autocrine VEGF upon the uptake of tumor-derived microvesicles containing oncogenic EGFR. Proc Natl Acad Sci U S A (2009) 106:3794-9. doi:10.1073/pnas. 0804543106

2. Skog J, Wurdinger T, van Rijn S, Meijer DH, Gainche L, Sena-Esteves M, et al. Glioblastoma microvesicles transport RNA and proteins that promote tumor growth and provide diagnostic biomarkers. Nat Cell Biol (2008) 10:1470-6. doi: $10.1038 /$ ncb 1800

3. Al-Nedawi K, Meehan B, Micallef J, Lhotak V, May $\mathrm{L}$, Guha A, et al. Intercellular transfer of the oncogenic receptor EGFRvIII by microvesicles derived from tumour cells. Nat Cell Biol (2008) 10:619-24. doi:10.1038/ncb1725

4. Gabriel K, Ingram A, Austin R, Kapoor A, Tang D, Majeed F, et al. Regulation of the tumor suppressor
PTEN through exosomes: a diagnostic potential for prostate cancer. PLoS One (2013) 8:e70047. doi:10.1371/journal.pone.0070047

5. Putz U, Howitt J, Doan A, Goh CP, Low LH, Silke $\mathrm{J}$, et al. The tumor suppressor PTEN is exported in exosomes and has phosphatase activity in recipient cells. Sci Signal (2012) 5:ra70. doi:10.1126/ scisignal.2003084

6. Sawai H, Yasuda A, Ochi N, Ma J, Matsuo Y, Wakasugi $\mathrm{T}$, et al. Loss of PTEN expression is associated with colorectal cancer liver metastasis and poor patient survival. BMC Gastroenterol (2008) 8:56 doi:10.1186/1471-230X-8-56

7. Pettaway CA, Pathak S, Greene G, Ramirez E, Wilson MR, Killion JJ, et al. Selection of highly metastatic variants of different human prostatic carcinomas using orthotopic implantation in nude mice. Clin Cancer Res (1996) 2: 1627-36.

8. Conley-LaComb MK, Saliganan A, Kandagatla P, Chen YQ, Cher ML, Chinni SR. PTEN loss mediated Akt activation promotes prostate tumor growth and metastasis via CXCL12/CXCR4 signaling. Mol Cancer (2013) 12:1-16. doi:10.1186/ 1476-4598-12-85

9. Zhang LL, Liu J, Lei S, Zhang J, Zhou W, Yu HG. PTEN inhibits the invasion and metastasis of gastric cancer via downregulation of FAK expression. Cell Signal (2014) 26:1011-20. doi:10. 1016/j.cellsig.2014.01.025

10. Gunduz N, Fisher B, Saffer EA. Effect of surgical removal on the growth and kinetics of residual tumor. Cancer Res (1979) 39:3861-5.

11. Fisher B, Gunduz N, Saffer EA. Influence of the interval between primary tumor removal and chemotherapy on kinetics and growth of metastases. Cancer Res (1983) 43:1488-92.

12. Fisher B, Gunduz N, Coyle J, Rudock C, Saffer E. Presence of a growth-stimulating factor in serum following primary tumor removal in mice. Cancer Res (1989) 49:1996-2001.

13. Basu S, Bhattacharyya SN. Insulin-like growth factor-1 prevents miR-122 production in neighboring cells to curtail its intercellular transfer to ensure proliferation of human hepatoma cells. Nucleic Acids Res (2014) 42:7170-85. doi:10.1093/nar/gku346

14. Liu Y, Zhao L, Li D, Yin Y, Zhang CY, Li J, et al. Microvesicle-delivery miR-150 promotes tumorigenesis by up-regulating VEGF, and the neutralization of miR-150 attenuate tumor development. Protein Cell (2013) 4:932-41. doi:10.1007/s13238013-3092-z

15. Aucher A, Rudnicka D, Davis DM. MicroRNAs transfer from human macrophages to hepato-carcinoma cells and inhibit proliferation. J Immunol (2013) 191:6250-60. doi:10.4049/ jimmunol.1301728

16. Katakowski M, Buller B, Zheng X, Lu Y, Rogers $\mathrm{T}$, Osobamiro O, et al. Exosomes from marrow stromal cells expressing miR-146b inhibit glioma growth. Cancer Lett (2013) 335:201-4. doi:10. 1016/j.canlet.2013.02.019

Conflict of Interest Statement: The author declares that the research was conducted in the absence of any commercial or financial relationships that could be construed as a potential conflict of interest.

Received: 28 March 2014; accepted: 16 June 2014; published online: 09 July 2014.

Citation: Al-Nedawi $K$ (2014) The Yin-Yang of microvesicles (exosomes) in cancer biology. Front. Oncol. 4:172. doi: 10.3389/fonc.2014.00172

This article was submitted to Molecular and Cellular Oncology, a section of the journal Frontiers in Oncology. Copyright (c) 2014 Al-Nedawi. This is an open-access article distributed under the terms of the Creative Commons Attribution License (CC BY). The use, distribution or reproduction in other forums is permitted, provided the original author(s) or licensor are credited and that the original publication in this journal is cited, in accordance with accepted academic practice. No use, distribution or reproduction is permitted which does not comply with these terms. 